\title{
Mental Health and Behavior Difficulties for Children and Adolescents, during the COVID-19 Pandemic Lockdown
}

\author{
T. Gkatsa* \\ https://orcid.org/0000-0002-2060-7171 \\ Pedagogy Department of Primary School, University of Ioannina, Greece \\ *Corresponding Author: T. Gkatsa; tgkatsa@uoi.gr
}

\begin{abstract}
Coronavirus disease 2019 (COVID-19) has been associated with adverse effects on the mental health and behavior of children and adolescents. Living conditions during the pandemic period, fear of death, threat and restrictive measures -such as isolation, limitation of social contacts, closure of the economy, loss of routine and activities- have been associated with psychosocial burden. Research studies confirm a wide range of emotional and mental difficulties, such as irritability, anxiety, distress, difficulty concentrating more serious psychosocial effects -such as depression, anxiety, post-traumatic stress disorder and discomfort, substance use, and suicide. In pandemic conditions, during which social isolation and deprivation of social contacts prevail, children and adolescents show behavioral difficulties. Children regress to younger behaviors, manifesting forms of presocial behavior, reactive / provocative, aggressive behavior, negation, upset, outbursts of anger, behavior without control, physical symptoms (hurts) and general difficulties of adjustment. Adolescents exhibit digital media addiction behaviors and risky behaviors. Significant deterioration is observed in the behavior of children with special needs, mental illness and social vulnerability.
\end{abstract}

Keywords: mental behavioral difficulties; children; adolescents; pandemic; COVID-19 lock down

\section{INTRODUCTION}

Coronavirus disease 2019 (COVID-19) refers to the severe acute respiratory syndrome coronavirus 2 (SARSCoV-2). The Covid-19 virus appeared in Wuhan, China, in December 2019 and it was soon declared as COVID 19 pandemic in March, 2020 [1].

A wide range of studies in many countries -such as in China, India, Brazil, U.S.A., Spain, Italy and Germany- confirms the negative effects of the pandemic on the mental health and behavior of children and adolescents [2].

The experts mention that children are less at risk of severe coronavirus 2 (SARS-CoV-2) and have a much lower mortality rate. However, during the pandemic, living conditions and measures adversely and multifacetedly affected the mental health and behavior of children and adolescents [3], [4].

The pandemic, the influence of the media, the closure of schools, the lack of contact with friends are stressful conditions and affect children and adolescents, who have limited ability to understand the conditions and the new situation [5]. The World Health Organization (WHO) and the United Nations International Children's Emergency Fund (UNICEF), through the Lancet Commission, in April 2020, states that children and adolescents, in many countries, have interrupted their education for months and have lost social contact with their classmates. Some children and adolescents are hungry resulting in a weakened immune system. Others are exposed to violence, abuse and are under the influence of adverse conditions that threaten their well-being and mental health [6]. Additional information from other sources provides epidemiological evidence on the threat to adolescent girls' sexual health. According to this source of information, human rights are more widely affected [7].

Children do not have the cognitive skills and emotional strategies to understand and deal with the difficulties of the situation. They have difficulty communicating adequately and managing their emotions. At the same time, adolescents are in the age of transition from childhood to adulthood and are exhibit by the typical characteristics of liquidity and vulnerability [8], [9], [10]. Adverse conditions in the pandemic, restriction, social 
isolation, idiosyncratic social relationships not only affect the mental health and behavior children and adolescents but also threaten their normal development. [11].

It is worth noting, however, that the burden on children and adolescents depends on their exposure to previous threatening conditions, emergencies from the level of physical and mental health, socioeconomic conditions of the family and the wider cultural environment [5], [1].

This article presents in detail the negative effects of the COVID-19 pandemic on the mental health and behavior for children and adolescents. As a whole, all children and adolescents, in all countries surveyed, with or without pre-existing difficulties, show mental and behavioral difficulties in all phases and conditions of the pandemic.

\section{COVID-19 PANDEMIC AND MENTAL DIFFICULTIES FOR CHILDREN AND ADOLESCENTS}

Children with COVID-19 have exhibited some warning signs of mental health problems. Indications for the risk of developing mental health problems include a) abnormal reactions to daily functions (sleep, food refusal or overeating, excessive aggression or fear, anxiety and depression, b) mood swings (increased aggression and fear), c) abnormal behaviors (inappropriate behavior and denial, uncontrolled behavior -e.g., causing harm to other people, self-harming behavior, complaints that it cannot be stopped), d) physical symptoms (feeling uncomfortable, physical pain -such as headache, stomachache- without obvious causes) [12].

An important review of studies in a total of 22,996 children and adolescents, identifies psychological and behavioral difficulties in children and adolescents with or without pre-existing difficulties. It is observed that they are negatively affected by pandemic conditions (79.4\%), feel fear for the virus (22.5\%), feel boredom (33.3\%) and show some disorder (21.3\%). In addition, anxiety symptoms are reported; 34\%, 34.5\% depression, $42.3 \%$ irritability, whereas $30.8 \%$ reluctance and boredom [13].

A study reviews up to May 2020 highlighted significant study findings on the adverse effects of the COVID-19 pandemic on the mental health and behavior of children and adolescents. According to it, during the pandemic, children and adolescents experience depression, anxiety, and psychological stress [12], [14], [15], [16]. These findings are consistent with those of another study in a sample of 2,330 children, which reported symptoms of depression (22.6\%) and anxiety (18.9\%). In a larger study in China, based on a sample of 8,079 children and adolescents, aged 12 to 18 years, it was found that $43.7 \%$ of the sample had symptoms of depression and $37.4 \%$ anxiety symptoms [12], as well as mental distress. In the same area, another study found that $2.4 \%$ of children developed physical symptoms, particularly physical pain, breathing difficulties and sleep difficulties [16], [17].

Brooks et al. (2020) in their review, report that $28 \%$ to $34 \%$ of children show symptoms of post-traumatic stress disorder (PTSD) [18]. Interestingly, a study in America, which focused on the effect of H1N1 and SARSCov on children, shows that $30 \%$ of the children who were exposed to quarantine developed PTSD symptoms. PTSD causes stress and other adverse effects on the mental health of children and adolescents [19], [20]. Girls are twice as likely to develop PTSD symptoms. The PTSD syndrome has a detrimental effect on brain development, especially in childhood. More specifically, it is reported that it causes permanent damage to the brain circuits of the anterior lobe and because of this someone feels threatened due to impaired regulation of the brain [20], [21]. In addition, PTSD refers to the manifestation of sadness, which comes from an unresolved emotional state in the family or at school [12].

Two studies collect research data from parents. The first had a sample of 320 children and in its results reported symptoms (according to DSM-V) such as attachment at 37\%, carelessness at 33\%, anxiety at 32\%, obsessions at $22 \%$, fear of death at $22 \%$, difficulty sleeping at $22 \%$, poor appetite at $18 \%$, fatigue at $17 \%$, nightmares at $14 \%$ and discomfort at 13\% [24]. The second study was conducted in the U.S.A. Based on a sample of 137 parents, it was found that the majority of them, at $40.1 \%$, observed signs of emotional and social discomfort, $30.9 \%$ disagreed and some parents answered that they were not sure (6.3\%) [22]. As far as age is concerned, studies do not agree on whether older children or younger children or adolescents are more stressed [12], [14], [15]. In relation to gender, two out of three studies agree that girls are more likely to develop symptoms of depression and anxiety [13], [12]. Children living in areas with a high rate of infectivity showed a higher degree of depression and anxiety symptoms [14], [24]. 
Additionally, the results of a study in China showed that children in rural areas had more symptoms than urban children [12]. Another study confirms the findings and further observes that children and adolescents with clinical symptoms of depression, women and those who have a family member or a friend with coronavirus have higher levels of stress [5].

During the first phase of the pandemic, the adverse effects on mental health and behavior in children and adolescents were obvious. The first wave of the pandemic spread fear, panic and confusion. Early research in young Chinese children showed that the COVID-19 pandemic caused the same psychological burden as the previous SARS pandemic conditions and the avian epidemic [25]. Researchers explain that the fear and worry that someone may be infected probably contributes to the observance of hygiene measures of the general population but it also burdens the individual [26]. Deprivation of daily pleasurable activities (friends, entertainment, travels, excursions, walks) and strict restrictive measures (outings at certain times, movement control, interrogation and fines) cause a sense of helplessness and less interest in the future [1].

Furthermore, in the international literature, it is reported that some strains of the coronavirus have been associated with the occurrence of psychiatric disorders [27]. In a similar way to coronavirus, refers to appears to occur in borderline influenza A, B conditions, as they have been linked to a history of mood disorders [28]. It is important children and adolescents, who are neglected during the pandemic, are advised to be checked for their mental burden, after the end of the pandemic [5]. Changing circumstances have been found that reduce parental care and weaken supportive relationships and effective communication [29]. In addition, regarding parental care, the literature states that the mental burden of parents affects the mental burden of children and adolescents. Parents with high rates of discomfort report high levels of discomfort for their children [30]. This probably happens because parents are facing financial difficulties and because of these they themselves are mentally burdened. As a result, children and adolescents are affected by the vulnerability of their parents who are experiencing emotional distress, mental illness or substance use [31], [32], [33].

Moreover, in countries most affected, such as the U.S.A. and India, children and adolescents have more severe mental health and behavioral difficulties [1]. It is worth mentioning, at this point, the results of a review study on the psychosocial consequences of three respiratory, infectious, pandemic diseases. In particular, the review of Wang et al. (2020) identified 24 studies, in particular for SARS (10 studies), INUENZA (HINI-3 studies) and COVID-19 (11 studies) [29]. According to the results of the afore-mentioned studies, it was found that children during the period of pandemic diseases experience emotional difficulties anxiety, depression and fear as well as various other emotional reactions depending on their gender and age. Based on a review finding, the mental symptoms of children with a history of mental illness were worsened. In general, stressful conditions could increase the likelihood of adjustment disturbances worldwide [34].

\section{LOCKDOWN AND BEHAVIORAL DIFFICULTIES FOR CHILDREN AND ADOLESCENTS}

In the pandemic period, social isolation, online digital education / home schooling creates a new reality for children and adolescents. Due to social constraint, the effects on sociability and their social development are inevitable [35], [36], [37].

Fegert et al. (2019), in a review study, argue that social relationships between children and adolescents have been severely restricted to family members only [38]. The well-being of children and adolescents is affected by the ban on social contact, social exclusion, restriction of contact with classmates and friends, lack of joint educational time with classmates, restriction of leisure activities and stigmatization of family members or themselves in cases they have been infected with the virus [39], [40], [41], [42].

Everyday life changes and the relationships of the members in the family are reorganized. Home education is the new reality. Working from home forces parents to be constantly at home, whereas others who no longer work are burdened with fear and anxiety. Elderly grandparents are under the threat of death. The restrictive conditions of the pandemic period affect the relationships of family members and this burdens the mental health and well-being of children and adolescents [38]. 
In the reshaped social context, the behavior of young children is disturbed; it becomes provocative / contradictory, with outbursts of anger. Children with manifestations of disruptive behavior probably express their concern and emotional discomfort to their parents and caregivers. Parents often report difficulties in the behavior of young children and preschool children, who are often upset, show contradictory and provocative reactions, aggressive behavior when playing, despite their initial desire to participate. In many cases, relapse is also reported in younger behaviors -such as pacifier, bottle milk, toilet accidents, refusal to dress, attachment to adults, persistent demand, difficulty sleeping (nightmares, multiple awakenings at night, inability to sleep) [1].

In a very recent study by Liu et al. $(2020,2021)$ about the behavior of school-age children at home, behavioral problems were identified. According to the findings $4.7 \%$ - $10.3 \%$ difficult behaviors - such as pre-social behavior, difficulty in their relationship with peers, hyperactivity and carelessness, emotional problems [15], [16] are observed.

In relation to the above observation, Duan et al. (2020) add that emotional difficulty of children and adolescents have been associated with behavioral difficulties in pandemic conditions. More specifically, they found that high rates of depression were associated with smartphone (OR 1,411.95\%, DI 1.0099-1,180) and internet addiction (OR 1,844, 95\% CI 1.2009-2,9811) as well as in problems solving (OR 0.937, 95\% DI 0.923-0.951), [43].

Older children and adolescents live in conditions of social isolation, lack friends and social life, at the age when, according to E. Erikson, they form their identity. Under normal circumstances, young people form their psychosocial identity through contacts and social relationships [44]. Nevertheless, in pandemic conditions, the process of identity formation is suspended and they themselves are confused.

Young people, teenagers and students are called to suppress their social dynamics and because of this they suffer, they feel frustrated and nervous [1]. During lockdown, it is found that adolescents decreased physical activity, increased digital media exposure (screen time), and they were facing sleeping difficulties. Acute isolation increases social longing, which at the neurological level, is attributed as a function similar to, a stimulus to hunger, at a neuro-functional level. In times of crisis, there is a general feeling of psychological distress, with concomitant relapse behavior and external symptoms -such as sleeping difficulty, peer problems, isolation and depression [45].

In addition, the closure of schools brings an additional difficulty, because schools are a mechanism for dealing with young people's problems. Consequently, their closure resulted in young people being deprived of this possibility [46].

For young people, teenagers staying at home for a long time carries the risk of increasing the use of social media and forming a strong attitude of overestimating them. In many cases, they circulated dangerous views against the observance of the measures (masks, distances, gatherings) and encouraged them to take risky and dangerous behaviors. In many cases, these attitudes influenced the direction of behaviors of the type "I do not care about the measures and others", making themselves attractive and important because of this behavior. Young people and adolescents seem to be more concerned about government decisions on measures to curb the virus and less about the virus itself. Experts attribute this tendency to increased stress, depression, and decreased life satisfaction [47], [48]. These behavioral tendencies can also greatly damage the decision-making process of young people and especially ambitious ones. At this point, it is worth noting the impact that celebrities receive on social media and their attitude towards the epidemic [48].

Staying at home for a long time causes hysteria and paranoia due to lack of stimulation from stimuli outside the home. In addition, prolonged repression can lead to the desire to perform harmful acts [49]. There is a relative increase in self-injuries and suicides of young people, during school closures [50]. Regarding adolescents, there is still no research data to support the increase in rates of suicidal ideation and/or suicides [51],[52]. Despite the lack of research, there is evidence from previous research that adolescents increase risky behaviors -such as drug use and premature relationships- in times of disaster [52].

Children with special needs and children diagnosed with psychiatric illness are more vulnerable to the negative effects of the pandemic [53], [54. Children with pre-existing psychological burden, symptoms of depression and 
anxiety is shocked by the news of death [1]. A review of 221 studies in a sample of 33,398 children and adolescents shows that parents with children with Attention Deficit Hyperactivity Disorder (ADHD) experience deteriorating behavior and, in particular, report that their children exhibit angry behavior and cannot stay focused during their daily activities [55], [56]. In addition, children with symptoms of obsessive-compulsive disorder are exacerbated by stress [1]. It is also reported, for children on the autism spectrum and with neurocognitive disorders, that they become impulsive and this is attributed to the fact that their daily routine is destroyed [57], [55], [58], [46], [59].

Other studies highlight the link between quarantine and the exploitation and sexual abuse of children and adolescents [60]. Interpol also reports an increase in child pornography since the outbreak of the pandemic [60].

Children and adolescents from vulnerable groups, lower social classes, "unaccompanied" children / adolescents and refugees are at greater risk of developing behavioral and emotional difficulties, as they are at greater risk of malnutrition, poor hygiene and poor health [61].

In conclusion, according to the research data so far, it is concluded that the COVID-19 pandemic has been associated with serious adverse effects, affecting the well-being and more significantly the mental health and behavior of children and adolescents. In some cases, they may cause more serious or permanent problems that can damage their development. Early intervention and treatment may prevent adverse effects on development and later adulthood. Half a year after the outbreak of the pandemic, there is a strong need to investigate the mental health of children and adolescents [62] and to promote their mental health and quality of life [63].

\section{REFERENCES}

[1] Imran, N., Zeshan, M., \& Pervaiz, Z. (2020). Mental health considerations for children \& adolescents in COVID-19 Pandemic. Pakistan journal of medical sciences, 36(COVID19-S4), S67. https://dx.doi.org/10.12669\%2Fpjms.36.COVID19-S4.2759

[2] Ravens-Sieberer, U., Kaman, A., Erhart, M., Devine, J., Schlack, R., \& Otto, C. (2021). Impact of the COVID-19 pandemic on quality of life and mental health in children and adolescents in Germany. European child \& adolescent psychiatry, 1-11. https://doi.org/10.1007/s00787-021-01726-5

[3] Vlachos, J., Hertegård, E., \& Svaleryd, H. B. (2021). The effects of school closures on SARS-CoV-2 among parents and teachers. Proceedings of the National Academy of Sciences, 118(9). https://doi.org/10.1073/iti3721118

[4] Manivannan, M., Jogalekar, M. P., Kavitha, M. S., Maran, B. A. V., \& Gangadaran, P. (2021). A mini-review on the effects of COVID-19 on younger individuals. Experimental Biology and Medicine, 246(3), 293-297. https://doi.org/10.1177\%2F1535370220975118

[5] Dalton L, Rapa E, Stein A. Lancet. Child Adolesc Health. 2020 Mótoৎ 4 (5): 346-347. https://doi.org/10.1016/S2352-4642(20)30177-2

[6] Clark, A., Jit, M., Warren-Gash, C., Guthrie, B., Wang, H. H., Mercer, S. W., ... \& Jarvis, C. I. (2020). Global, regional, and national estimates of the population at increased risk of severe COVID-19 due to underlying health conditions in 2020: a modelling study. The Lancet Global Health, 8(8), e1003-e1017. https://doi.org/10.1016/S2214-109X(20)30264-3

[7] Bewa, J. M. (2021). School closures and teenage pregnancy. Bull World Health Organ, 99, 6-7. https://dx.doi.org/10.2471\%2FBLT.21.020121

[8] Swick, S. D., DECHANT, E., \& JELLINEK, M. S. (2002). Children of victims of September 11th: a perspective on the emotional and developmental challenges they face and how to help meet them. Journal of Developmental \& Behavioral Pediatrics, 23(5), 377-384. 
[9] Sturman, D. A., \& Moghaddam, B. (2011). The neurobiology of adolescence: changes in brain architecture, functional dynamics, and behavioral tendencies. Neuroscience \& Biobehavioral Reviews, 35(8), 17041712. https://doi.org/10.1016/j.neubiorev.2011.04.003

[10] Larsen, B., \& Luna, B. (2018). Adolescence as a neurobiological critical period for the development of higher-order cognition. Neuroscience \& Biobehavioral Reviews, 94, 179-195. https://doi.org/10.1016/j.neubiorev.2018.09.005

[11] Guessoum, S. B., Lachal, J., Radjack, R., Carretier, E., Minassian, S., Benoit, L., \& Moro, M. R. (2020). Adolescent psychiatric disorders during the COVID-19 pandemic and lockdown. Psychiatry research, 113264. https://doi.org/10.1016/j.psychres.2020.113264

[12] Zhou, Y., Zhou, Y., Song, Y., Ren, L., Ng, C. H., Xiang, Y. T., \& Tang, Y. (2021). Tackling the mental health burden of frontline healthcare staff in the COVID-19 pandemic: China's experiences. Psychological medicine, 51(11), 1955-1956. https://doi.org/10.1017/S0033291720001622

[13] Panda, P. K., Gupta, J., Chowdhury, S. R., Kumar, R., Meena, A. K., Madaan, P., ... \& Gulati, S. (2021). Psychological and behavioral impact of lockdown and quarantine measures for COVID-19 pandemic on children, adolescents and caregivers: a systematic review and meta-analysis. Journal of Tropical Pediatrics, 67(1), fmaa122. https://doi.org/10.1093/tropej/fmaa122

[14] Xie, X., Xue, Q., Zhou, Y., Zhu, K., Liu, Q., Zhang, J., \& Song, R. (2020). Mental health status among children in home confinement during the coronavirus disease 2019 outbreak in Hubei Province, China. JAMA pediatrics, 174(9), 898-900. doi: 10.1001/jamapediatrics.2020.1619

[15] Liu JJ, Bao Y, Huang X, Shi J, Lu L Lancet. Child Adolesc Health. 2020 May; 4(5):347-349. https://doi.org/10.1016/j.jad.2021.02.078

[16] Liu, S., Liu, Y., \& Liu, Y. (2020). Somatic symptoms and concern regarding COVID-19 among Chinese college and primary school students: A cross-sectional survey. Psychiatry research, 289, 113070. [PMC free article] [PubMed] [Google Scholar] [Ref list]. https://doi.org/10.1016/j.psychres.2020.113070

[17] Becker, S. P., \& Gregory, A. M. (2020). Editorial Perspective: Perils and promise for child and adolescent sleep and associated psychopathology during the COVID-19 pandemic.

https://doi.org/10.1111/jcpp.13278

[18] Brooks SK, Webster RK, Smith LE, Woodland L, Wessely S, Greenberg N, et al. The psychological impact of quarantine and how to reduce it: rapid review of the evidence. Lancet. 2020;395(10227):912-20. https://doi.org/10.1016/S0140-6736(20)30460-8

[19] Kar, N., \& Bastia, B. K. (2006). Post-traumatic stress disorder, depression and generalised anxiety disorder in adolescents after a natural disaster: a study of comorbidity. Clinical Practice and Epidemiology in Mental Health, 2(1), 1-7. https://cpementalhealth.biomedcentral.com/articles/10.1186/1745-0179-2-17

[20] Herringa, R. J. (2017). Trauma, PTSD, and the developing brain. Current Psychiatry Reports, 19(10), 1-9. https://link.springer.com/article/10.1007/s11920-017-0825-3

[21] Garza, K., \& Jovanovic, T. (2017). Impact of gender on child and adolescent PTSD. Current psychiatry reports, 19(11), 1-6. https://link.springer.com/article/10.1007/s11920-017-0830-6

[22] Rosen, Z., Weinberger-Litman, S.L., Rosenzweig, C., Rosmarin, D.H., Muennig, P., Carmody, E.R., Rao, S.T., \& Litman, L. (2020)., 2020. Anxiety and distress among the first community quarantined in the U.S. due to COVID-19: psychological implications for the unfolding crisis. https://doi.org/10.31234/osf.io/7eq8c

[23] Oosterhoff, B., Palmer, C.A., Wilson, J., \& Shook, N. (2020), 2020. Adolescents' motivations to engage in social distancing during the COVID-19 pandemic: associations with mental and social health. https://doi.org/10.1016/j.jadohealth.2020.05.004 
[24] Jiao W.Y., Wang L.N., Liu J., Fang S.F., Jiao F.Y., Pettoello-Mantovani M., Somekh E. Behavioral and emotional disorders in children during the COVID-19 epidemic. J. Pediatr. 2020; 221:264-266. (jlz,0375410). https://dx.doi.org/10.1016\%2Fj.jpeds.2020.03.013

[25] Huang, Y, Zhao, N. Chinese mental health burden during the COVID-19 pandemic. Asian J Psychiatry 2020; 51:102052. https://doi.org/10.1016/j.ajp.2020.102052

[26] Holling H, Schlack R, Petermann F, Ravens-Sieberer U, Mauz E. Psychopathological problems and psychosocial impairment in children and adolescents aged 3-17 years in the German population: prevalence and time trends at two measurement points (2003-2006 and 2009-2012): results of the KiGGS study: frst follow-up (KiGGS Wave 1). Bundesgesundheitsblatt Gesundheitsforschung Gesundheitsschutz. 2014;57(7):807-19. 16. https://europepmc.org/article/med/24950830

[27] Severance EG, Dickerson FB, Viscidi RP, Bossis I, Stallings CR, Origoni AE, et al. Coronavirus immunoreactivity in individuals with a recent onset of psychotic symptoms. Schizophr Bull. 2011;37(1):101-7. https://doi.org/10.1093/schbul/sbp052

[28] Okusaga O, Yolken RH, Langenberg P, Lapidus M, Arling TA, Dickerson FB, et al. Association of seropositivity for infuenza and Coronaviruses with history of mood disorders and suicide attempts. J Afect Disord. 2011;130(1-2):220-5. https://doi.org/10.1016/j.jad.2010.09.029

[29] Wang, C., Xiao, S., Sun, Y., Wang, J., \& Xu, T. (2020). Psychosocial impact of respiratory infectious disease pandemics on children: a systematic review.

[30] Rosen, Z., Weinberger-Litman, S.L., Rosenzweig, C., Rosmarin, D.H., Muennig, P., Carmody, E.R., Rao, S.T., \& Litman, L. (2020)., 2020. Anxiety and distress among the first community quarantined in the U.S. due to COVID-19: psychological implications for the unfolding crisis. https://doi.org/10.31234/osf.io/7eq8c

[31] Riley AW, Valdez CR, Barrueco S, Mills C, Beardslee W, Sandler I, et al. Development of a family-based program to reduce risk and promote resilience among families afected by maternal depression: theoretical basis and program description. Clin Child Fam Psychol Rev. 2008;11(1):12-29. DOI 10.1007/s10567-0080030-3

[32] Klein M. Kinder aus alkoholbelasteten Familien - Ein Überblick zu Forschungsergebnissen und Handlungsperspektiven. Suchttherapie. 2001;2(03):118-24. DOI: 10.1055/s-2001-16416

[33] Holling H, Schlack R, Petermann F, Ravens-Sieberer U, Mauz E. Psychopathological problems and psychosocial impairment in children and adolescents aged 3-17 years in the German population: prevalence and time trends at two measurement points (2003-2006 and 2009-2012): results of the KiGGS study: frst follow-up (KiGGS Wave 1). Bundesgesundheitsblatt Gesundheitsforschung Gesundheitsschutz. 2014;57(7):807-19. 16. https://europepmc.org/article/med/24950830

[34] Çakıroğlu, S., Ertaş, E., \& Alyanak, B. (2020). Letter to The Editor-The Covid-19 Pandemic and Mental Health as Issues Considered Within the Context of Adjustment Disorder and Psychosocial Interventions. Turk psikiyatri dergisi= Turkish journal of psychiatry, 31(2), 148-150.

https://irsc-cihr.gc.ca/e/documents/Camden-Initial-Knowledge-Synthesis-2020-06-22.pdf

[35] Cardenas, M. C., Bustos, S. S., \& Chakraborty, R. (2020). A 'parallel pandemic': The psychosocial burden of COVID-19 in children and adolescents. Acta Paediatrica, 109(11), 2187-2188.

https://doi.org/10.1111/apa.15536

[36] Stavridou, A., Stergiopoulou, A. A., Panagouli, E., Mesiris, G., Thirios, A., Mougiakos, T., ... \& Tsitsika, A. (2020). Psychosocial consequences of COVID-19 in children, adolescents and young adults: a systematic review. Psychiatry and Clinical Neurosciences. https://dx.doi.org/10.1111\%2Fpcn.13134 
[37] Loades, M. E., Chatburn, E., Higson-Sweeney, N., Reynolds, S., Shafran, R., Brigden, A., ... \& Crawley, E. (2020). Rapid systematic review: the impact of social isolation and loneliness on the mental health of children and adolescents in the context of COVID-19. Journal of the American Academy of Child \& Adolescent Psychiatry, 59(11), 1218-1239. https://dx.doi.org/10.1016\%2Fj.jaac.2020.05.009

[38] Fegert, J. M., Vitiello, B., Plener, P. L., \& Clemens, V. (2020). Challenges and burden of the Coronavirus 2019 (COVID-19) pandemic for child and adolescent mental health: a narrative review to highlight clinical and research needs in the acute phase and the long return to normality. Child and adolescent psychiatry and mental health, 14, 1-11. https://dx.doi.org/10.1186\%2Fs13034-020-00329-3

[39] Covid, C. D. C., Team, R., Covid, C. D. C., Team, R., COVID, C., Team, R., ... \& Skoff, T. (2020). Coronavirus disease 2019 in children-United States, february 12-april 2, 2020. Morbidity and Mortality Weekly Report, 69(14), 422. https://dx.doi.org/10.15585\%2Fmmwr.mm6914e4

[40] Giford-Smith ME, Brownell CA. Childhood peer relationships: social acceptance, friendships, and peer networks. J Sch Psychol. 2003;41(4):235-84. https://doi.org/10.1016/S0022-4405(03)00048-7

[41] Oberle E, Schonert-Reichl KA, Thomson KC. Understanding the link between social and emotional wellbeing and peer relations in early adolescence: gender-specifc predictors of peer acceptance. J Youth Adolesc. 2010;39(11):1330-42. DOI 10.1007/s10964-009-9486-9

[42] Loades, M. E., Chatburn, E., Higson-Sweeney, N., Reynolds, S., Shafran, R., Brigden, A., ... \& Crawley, E. (2020). Rapid systematic review: the impact of social isolation and loneliness on the mental health of children and adolescents in the context of COVID-19. Journal of the American Academy of Child \& Adolescent Psychiatry, 59(11), 1218-1239. https://doi.org/10.1016/j.jaac.2020.05.009

[43] Duan, L., \& Zhu, G. (2020). Psychological interventions for people affected by the COVID-19 epidemic. The lancet psychiatry, 7(4), 300-302. https://doi.org/10.1016/S2215-0366(20)30073-0

[44] Davis D, Clifton A. (1995). Psychosocial theory: Erikson Haverford University. Department of Psychology. https://dx.doi.org/10.12669\%2Fpjms.36.COVID19-S4.2759

[45] Douglas, P. K., Douglas, D. B., Harrigan, D. C., \& Douglas, K. M. (2009). Preparing for pandemic influenza and its aftermath: mental health issues considered. International journal of emergency mental health, 11(3), 137. https://www.researchgate.net/profile/Pamela_Douglas4/publication/44568839_Preparing_for_pande mic_influenza_and_its_aftermath_Mental_health_issues_considered/links/0c96052b3e3d0f12a2000000/ Preparing-for-pandemic-influenza-and-its-aftermath-Mental-health-issues-considered.pdf

[46] Lee J. Mental health effects of school closures during COVID-19. Lancet Child Adolesc Health. 2020 Jun; 4(6):421. https://doi.org/10.1016/S2352-4642(20)30109-7

[47] Magson, N. R., Freeman, J. Y., Rapee, R. M., Richardson, C. E., Oar, E. L., \& Fardouly, J. (2021). Risk and protective factors for prospective changes in adolescent mental health during the COVID-19 pandemic. Journal of youth and adolescence, 50(1), 44-57. doi: 10.1007/s10964-020-01332-9.

[48] Gao, J, Zheng, P, Jia, Y, Chen, H, Mao, Y, Chen, S, Wang Y, Fu H, Dai J. Mental health problems and social media exposure during COVID-19 outbreak. Plos One 2020; 15(4):e0231924. https://doi.org/10.1371/journal.pone.0231924

[49] Pfefferbaum, B, North, CS. Mental health and the Covid-19 pandemic. N Engl J Med 2020; 383(6):510-512. DOI: 10.1056 / NEJMp2008017

[50] Snape, MD, Viner, RM. COVID-19 in children and young people. Science 2020; 370(6514):286-8. DOI: 10.1126 / science. abd6165 
[51] McIntyre, R. S., \& Lee, Y. (2020). Projected increases in suicide in Canada as a consequence of COVID-19. Psychiatry research, 290, 113104. https://doi.org/10.1016/j.psychres.2020.113104

[52] Hagan, J. F. (2005). Psychosocial implications of disaster or terrorism on children: A guide for the pediatrician. Pediatrics, 116(3), 787-795. DOI: https://doi.org/10.1542/peds.2005-1498

[53] De Figueiredo, C. S., Sandre, P. C., Portugal, L. C. L., Mázala-de-Oliveira, T., da Silva Chagas, L., Raony, Í., ... \& Bomfim, P. O. S. (2021). COVID-19 pandemic impact on children and adolescents' mental health: biological, environmental, and social factors. Progress in Neuro-Psychopharmacology and Biological Psychiatry, 106, 110171. doi: 10.1016/j.pnpbp.2020.110171.

[54] Jefsen, O. H., Rohde, C., Nørremark, B., \& Østergaard, S. D. (2021). Editorial Perspective: COVID-19 pandemic-related psychopathology in children and adolescents with mental illness. Journal of child psychology and psychiatry, 62(6), 798-800. https://doi.org/10.1111/jcpp.13292

[55] Panda, P. K., Gupta, J., Chowdhury, S. R., Kumar, R., Meena, A. K., Madaan, P., ... \& Gulati, S. (2021). Psychological and behavioral impact of lockdown and quarantine measures for COVID-19 pandemic on children, adolescents and caregivers: a systematic review and meta-analysis. Journal of Tropical Pediatrics, 67(1), fmaa122. doi: 10.1093/tropej/fmaa122.

[56] Cortese S, Coghill D, Santosh P, Hollis C, Simonoff E, European ADHD Guidelines Group. Starting ADHD medications during the COVID-19 pandemic: Recommendations from the European ADHD Guidelines Group. Lancet Child Adolesc.Health 2020; 4: e15. https://www.thelancet.com/pdfs/journals/lanchi/PIIS2352-4642(20)30144-9.pdf

[57] O’Sullivan, K., Clark, S., McGrane, A., Rock, N., Burke, L., Boyle, N., ... \& Marshall, K. (2021). A qualitative study of child and adolescent mental health during the COVID-19 pandemic in Ireland. International journal of environmental research and public health, 18(3), 1062. https://doi.org/10.3390/ijerph18031062

[58] Rath B, Donato J, Duggan A, Perrin K, Bronfin DR, Ratard R, VanDyke R, Magnus MJ Health Care Poor Underserved. 2007 May; 18(2):405-17. DOI 10.1007/s11920-017-0776-8.

DOI 10.1007/s10567-008-0030-3

[59] Bertelli OM, Scuticchio D, Bianco A, Buonaguro FE, Laghi F, Ghelma F, et al. Advices for managing the COVID-19 outbreak and the associated factors of mental distress for people with intellectual disability and autism spectrum disorder with high and very high support needs. Version 1.5. SIDiN (Italian Society for Neurodevelopmental Disorders). [Google Scholar]. https://www.wpanet.org/post/managing-covid-19related-mental-distress-for-people-with-high-and-very-high-support-needs

[60] Europol. Catching the virus cybercrime, disinformation and the COVID-19 pandemic. https://www.europol.europa.eu/publications-documents/catching-virus-cybercrime-disinformationand-covid-19-pandemic. 2020.

[61] Ghosh, R., Dubey, M. J., Chatterjee, S., \& Dubey, S. (2020). Impact of COVID-19 on children: special focus on the psychosocial aspect. Minerva Pediatrica, 72(3), 226-235. https://doi.org/10.23736/s0026-4946.20.05887-9

[62] Novins, D. K., Stoddard, J., Althoff, R. R., Charach, A., Cortese, S., Cullen, K. R., ... \& Simonoff, E. (2021). Editors' note and special communication: Research priorities in child and adolescent mental health emerging from the COVID-19 pandemic. https://doi.org/10.1016/j.jaac.2021.03.005

[63] Ravens-Sieberer, U., Kaman, A., Erhart, M., Devine, J., Schlack, R., \& Otto, C. (2021). Impact of the COVID-19 pandemic on quality of life and mental health in children and adolescents in Germany. European child \& adolescent psychiatry, 1-11. https://link.springer.com/article/10.1007/s00787-021-01726-5?s=09 